\title{
Antimicrobial Effects of a Hexapetide KCM21 against Pseudomonas syringae pv. tomato DC3000 and Clavibacter michiganensis subsp. michiganensis
}

\author{
Jeahyuk Choi ${ }^{1,2}$, Kwang-Hyun Baek ${ }^{2}$ and Eunpyo Moon ${ }^{1 *}$ \\ ${ }^{1}$ Department of Biological Science, Ajou University, Suwon 442-749, Korea \\ ${ }^{2}$ School of Biotechnology, Yeungnam University, Gyengsan 712-749, Korea
}

(Received on February 3, 2014; Revised on June 18, 2014; Accepted on June 19, 2014)

Antimicrobial peptides (AMPs) are small but effective cationic peptides with variable length. In previous study, four hexapeptides were identified that showed antimicrobial activities against various phytopathogenic bacteria. KCM21, the most effective antimicrobial peptide, was selected for further analysis to understand its modes of action by monitoring inhibitory effects of various cations, time-dependent antimicrobial kinetics, and observing cell disruption by electron microscopy. The effects of KCM21 on Gram-negative strain, Pseudomonas syringae pv. tomato DC3000 and Gram-positive strain, Clavibacter michiganensis subsp. michiganensis were compared. Treatment with divalent cations such as $\mathrm{Ca}^{2+}$ and $\mathrm{Mg}^{2+}$ inhibited the bactericidal activities of KCM21 significantly against $P$. syringae pv. tomato DC3000. The bactericidal kinetic study showed that KCM21 killed both bacteria rapidly and the process was faster against $C$. michiganensis subsp. michiganensis. The electron microscopic analysis revealed that KCM21 induced the formation of micelles and blebs on the surface of $P$. syringae pv. tomato DC3000 cells, while it caused cell rupture against $C$. michiganensis subsp. michiganensis cells. The outer membrane alteration and higher sensitivity to $\mathrm{Ca}^{2+}$ suggest that KCM21 interact with the outer membrane of $P$. syringae pv. tomato DC3000 cells during the process of killing, but not with $C$. michiganensis subsp. michiganensis cells that lack outer membrane. Considering that both strains had similar sensitivity to KCM21 in LB medium, outer membrane could not be the main target of KCM21, instead common compartments such as cytoplasmic membrane or internal macromolecules might be a possible target(s) of KCM21.

Keywords : antimicrobial synthetic peptides, bactericidal

*Corresponding author.

Phone) +82-031-219-2620, FAX) +82-031-219-1615

E-mail)emoon@ajou.ac.kr kinetics, electron microscopy, plant disease control

Bacterial diseases of plants are less prevalent than those caused by fungi and viruses; however, they are often extremely problematic for the commercial agriculture industry. This is because once the bacterial disease is established; it develops very rapidly, resulting in great reductions in yield or crop quality. Additionally, novel plant bacterial diseases have been rapidly emerging (Anderson et al., 2004). Antibiotics for prophylactic treatment of bacterial plant diseases are limited in availability, use, and efficacy, and therapeutic use is largely ineffective. Only two antibiotics, streptomycin and oxytetracycline, are widely used for treatment of bacterial diseases of plants in the United States. No new antibiotics are expected to be used in plant agriculture owing to the high costs of development, regulatory constraints, and environmental and human health concerns (Vidaver, 2002).

Antimicrobial peptides (AMPs) are promising alternatives to conventional agricultural chemicals or antibiotics that are facing challenges such as the emergence of antibioticresistant strains, regulatory constraints, and environmental and public health concerns (Sundin and Bender, 1993). AMPs are small $(<10 \mathrm{kDa})$ cationic and amphipathic peptides of variable length, sequence and structure that serve as important components of the natural defense of most living organisms including plants, bacteria, insects and other animals against invading pathogens (Reddy et al., 2004; Yedery and Reddy, 2005). Intensive studies have been conducted to isolate and characterize peptides from various tissue sources, and they have been found to have a broad spectrum of activity and selectivity, low eukaryotic cytotoxicity, and unique modes of action and cellular targets (Brogden, 2005; Hancock and Lehrer, 1998; Hancock and Sahl, 2006; Sal-Man et al., 2002; Yeaman and Yount, 2003). During the past decades, the potency of AMPs has been demonstrated against bacteria, fungi, and 
enveloped viruses (Lemaitre and Hoffmann, 2007).

There are several drawbacks to the practical application of AMPs found in various tissue sources of living organisms. For example, the development of new AMPs from organic tissues requires long term efforts for screening and characterization. Furthermore, their practical use is often limited due to a low level of activity and/or poor bioavailability (Blondelle et al., 1996). As an alternative, positional scanning approach of mixture-based synthetic combinatorial libraries (SCLs) was introduced in 1990s. An SCL is made up of tens of millions of peptide sequences, and positional scanning of such libraries has enabled successful identification of antimicrobial peptides with new or novel properties in a short period of time (Houghten et al., 1991, 1992, 1999; Houghten, 2000). In addition, the SCL approach has been used to improve the activity of existing antimicrobial amphipathic peptides. A tenfold enhancement in activity was obtained during screening of a SCL built around an amphipathic 18-mer peptide sequence known to have antimicrobial activity (Blondelle et al., 1996). Many AMP antibiotics have been selected based on SCL approaches during the last decades, most of which were targeted toward human pathogens. SCL approaches have also been applied for plant pathogens; however, most AMP selections experiments were designed to target fungal pathogens (Lopez-Garcia et al., 2000, 2002; Munoz et al., 2007).

The rapid emergence of bacterial strains causing plant diseases that are resistant to many drugs underscores the need for new control agents. In a previous study, four novel hexapeptides were selected through rapid screening of a synthetic combinatorial library (Choi and Moon, 2009). In the study, the minimal effective concentrations (MECs) of four hexapeptides were evaluated against 20 phytopathogenic bacteria. No sign of cytotoxicity was observed when the four hexapeptides were subjected to MTT \{3-(4,5-dimethylthiazol-2yl)-2,5-diphenyl-2Htetrazolium bromide assay in mammalian and mouse cell lines. The hexapeptide KCM21 was the most effective among the four hexapeptides. Application of KCM21 to Chinese cabbage leaf inoculated with Pectobacterium carotovorum subsp. carotovorum showed complete abolishment of disease development in a dose dependent manner (Choi and Moon, 2009).

In this study, two bacterial strains, Pseudomonas syringae pv. tomato DC3000 and Clavibacter michiganensis subsp. michiganensis, were employed to understand the antimicrobial activity of synthetic hexapeptide KCM 21, since each strain is a classic plant pathogenic bacterium representing typical Gram-negative and Gram-positive strain respectively. In the previous study KCM21 showed similar bactericidal activities for both stains. The effects of KCM21 on the two typical strains were compared by using kinetic study and electron microscope (EM) analysis. Impact of KCM21 on cell-structure was quite different; cell lysis was seemed to be preferred for $C$. michiganensis subsp. michiganensis, while surface alterations were prominent for $P$. syringae pv. tomato DC3000. The bactericidal activities of KCM21 were significantly interfered by divalent ions for $P$. syringae pv. tomato DC3000 but not for $C$. michiganensis subsp. michiganensis.

Identification of small effective AMPs and understanding their modes of actions would allow us to find a new way to control plant disease in agriculture.

\section{Materials and Methods}

Bacterial strains and KCM21 peptide. C. michiganensis subsp. michiganensis (KACC 20122) was obtained from the Korean Agricultural Culture Collections (KACC, Suwon, Korea) and P. syringae pv. tomato DC3000 (NCPPB 4369) was acquired from the National Collection of Plant Pathogenic Bacteria (NCPPB, York, UK) and maintained in our laboratory. Both strains were grown in Luria-Bertani (LB) media at $30^{\circ} \mathrm{C}$.

The sequences and properties of the four selected hexapeptides (KCM11, KCM12, KCM21, and KRS22) have been described previously (Choi and Moon, 2009). Briefly, the hexapeptide KCM21 (KWWWRW-NH2) was purchased from Peptron Co. (Daejeon, Korea) and purified by preparative reversed-phase high-pressure liquid chromatography with a Shiseido Capcell Pak C18 column. The peptide identity was confirmed by mass analysis with a HP 1100 series LC/MSD, after which it was dissolved in $50 \%$ dimethyl sulfoxide (final conc. $5 \mathrm{mM}$ ) and stored in aliquots at $-20^{\circ} \mathrm{C}$ (Choi and Moon, 2009).

Minimum inhibitory concentration (MIC) and minimum bactericidal concentration (MBC). Antimicrobial activities of the peptides were briefly measured based on the relative growth rate using a microtiter plate assay as previously described (Lopez-Garcia et al., 2002). In the assay, $180 \mu \mathrm{l}$ of diluted overnight culture (adjusted to $5 \times 10^{5}$ cells with LB) was mixed with $20 \mu$ of 10 $\times$ peptide stock solution and incubated for 16 to $48 \mathrm{~h}$ with gentle shaking $(80 \mathrm{rpm})$. For MIC assay, two-fold dilution series of KCM21 ranging from $3.125 \mu \mathrm{M}$ to $200 \mu \mathrm{M}$ were applied. The MIC was determined as the lowest concentration of the peptide that prevented visible turbidity, as measured at $595 \mathrm{~nm}$ using a micro plate reader 
(BioRad). Visible turbidity was determined by the OD readings of tested samples that were significantly greater than that of the medium, i.e. background (Concannon et al., 2003). To evaluate the effects of various cations $\left(\mathrm{K}^{+}, \mathrm{Ca}^{2+}\right.$ and $\left.\mathrm{Mg}^{2+}\right)$, cultures were supplemented with proper salts at final concentrations of $0.3 \mathrm{mM}, 0.6 \mathrm{mM}$, and $1.2 \mathrm{mM}$, respectively. For glycerol, cultures were supplemented with final concentrations of $0.75 \%, 1.5 \%$, and $3.0 \%$ instead.

MBC was determined in agar plates. An aliquot of $5 \mu 1$ of liquid culture was taken from each treated well by multipipette and transferred to a fully dried plate and incubated for $16-36 \mathrm{~h}$. The MBC was determined as the lowest concentration allowing no visible colony formation in the LB plate. When formation of an intermediate colony followed by formation of an intact colony, the MBC was taken to be the average of the final two dilutions. In all treatments, at least three replicates were prepared with at least two independent experiments. The deviations between the replications or independent experiments were usually less than two fold, if any. The observed values come from one set of experiment were plotted in graphs.

Bactericidal assay. The bactericidal assay was performed according to the procedures described by Miyasaki et al. (1998) with a slight modification. Briefly, bacterial cells were grown in LB broth up to mid-log phase. They were collected and resuspended in Na-phosphate buffer (10 $\mathrm{mM}, \mathrm{pH} 7.5$ ) with or without $0.3 \mathrm{mM}$ of $\mathrm{CaCl}_{2}$. Bacterial suspension was adjusted about to $5 \times 10^{7}$ cells $/ \mathrm{ml}$ by using spectrophotometer at $595 \mathrm{~nm}$. Bacterial suspension $(90 \mu \mathrm{l})$ was mixed with $10 \mu \mathrm{l} \mathrm{KCM} 21$ at eight different concentrations (half dilution series of $100 \mu \mathrm{M}$ ) and the reactions were incubated for various times up to $60 \mathrm{~min}$ in room temperature. At each interval, $5 \mu \mathrm{l}$ of suspension was taken and applied to a fully dried LB plate and incubated for 16-36 h. It was not easy to define the MBC as the same way with previous experiments since reasonable amount of variations were observed in treatments against $P$. s. pv. tomato DC3000. Statistical analysis was performed to calculate means as well as standard deviations by using 'Microsoft excel' functions.

EM analysis. For specimen preparation, bacterial cells were grown in LB broth to the exponential phase, harvested by centrifugation, washed twice and suspended with 10 $\mathrm{mM}$ sodium phosphate buffer. Approximately $1 \times 10^{7}$ cells/ $\mathrm{ml}$ were then incubated at $30^{\circ} \mathrm{C}$ for 30 min with $\mathrm{KCM} 21$. For each treatment, two different concentrations were applied; a sub-lethal and lethal level $(6.25 \mu \mathrm{M}$ and $100 \mu \mathrm{M}$, respectively). For transmission electron microscopy (TEM),
$5 \mu 1$ of the suspension was deposited into a carbon-coated grid and negatively stained with $0.5 \%$ uranyl acetate. The grids were examined using a JEOL JEM 100B electron microscope (Japan Electron Ortics Laboratory, Japan).

For SEM, the volume was adjusted to $50 \mu 1$ and each sample was spread on a poly(l-lysine)-coated glass slide ( $c a$. $18 \mathrm{~mm} \times 18 \mathrm{~mm}$ ) to immobilize the bacterial cells. Glass slides were incubated at $30^{\circ} \mathrm{C}$ for $30 \mathrm{~min}$, after which the slide-immobilized cells were fixed with Karnovsky's fixative solution at $4^{\circ} \mathrm{C}$ for $24 \mathrm{~h}$ and then washed three times for $15 \mathrm{~min}$ each with $0.05 \mathrm{M}$ cacodylate buffer. They were then post-fixed with $1 \%$ osmic acids for $3 \mathrm{~h}$, washed 3 times for $15 \mathrm{~min}$ each with $0.05 \mathrm{M}$ cacodylate buffer and dehydrated with a graded ethanol series. After critical-point drying and gold coating, the samples were observed with a scanning microscope (Hitachi S-2460N, Japan).

\section{Results and Discussion}

Adverse effects of cations and glycerol on the MIC and MBC of KCM21. To monitor the inhibitory effects of cations and glycerol on the bactericidal activity of KCM21, the minimum inhibitory concentration (MIC) and minimum bactericidal concentration (MBC) were evaluated in the presence of monovalent ion $\left(\mathrm{K}^{+}\right)$, divalent ions $\left(\mathrm{Ca}^{2+}\right.$, $\mathrm{Mg}^{2+}$ ) and glycerol known as a membrane stabilizer. Both the MIC and MBC enable monitoring of antimicrobial activities; however, if there is a difference between the two values, the gap can be used to evaluate any bacteriostatic characteristics in the antimicrobial mechanism of KCM21.

The MIC of the Gram-positive strain C. michiganensis subsp. michiganensis was increase by addition of various cations and glycerol. Divalent cations $\left(\mathrm{Ca}^{2+}\right.$ and $\left.\mathrm{Mg}^{2+}\right)$ increased the MIC up to $25 \mu \mathrm{M}$ from $12.5 \mu \mathrm{M}$ at the concentration of $1.2 \mathrm{mM}$. The pattern of increase was dosedependent. The effects of KCL and glycerol were less significant; they increased the MIC to 1.6 fold at their highest concentrations (Fig. 1). The fold increase of MIC was limited to 2 fold or less for C. michiganensis subsp. michiganensis cells. The divalent cations, $\mathrm{Ca}^{2+}$, and $\mathrm{Mg}^{2+}$ showed similar fold-increase as well as dose-dependent increase pattern suggesting that the two divalent cations share similar advert mechanism against the growth inhibition activity of KCM21 for the Gram-positive strain C. $m$. subsp. michiganensis. The MBCs of KCM21 were altered by supplementations of various cations and glycerol; however the effects were marginal for $C$. michiganensis subsp. michiganensis. Divalent cations $\left(\mathrm{Ca}^{2+}\right.$ and $\left.\mathrm{Mg}^{2+}\right)$ slightly increased the MBC to $25 \mu \mathrm{M}$ from $18.8 \mu \mathrm{M}$. Glycerol did not alter the MBC. $\mathrm{KCl}$ seemed to decrease the MBC to 


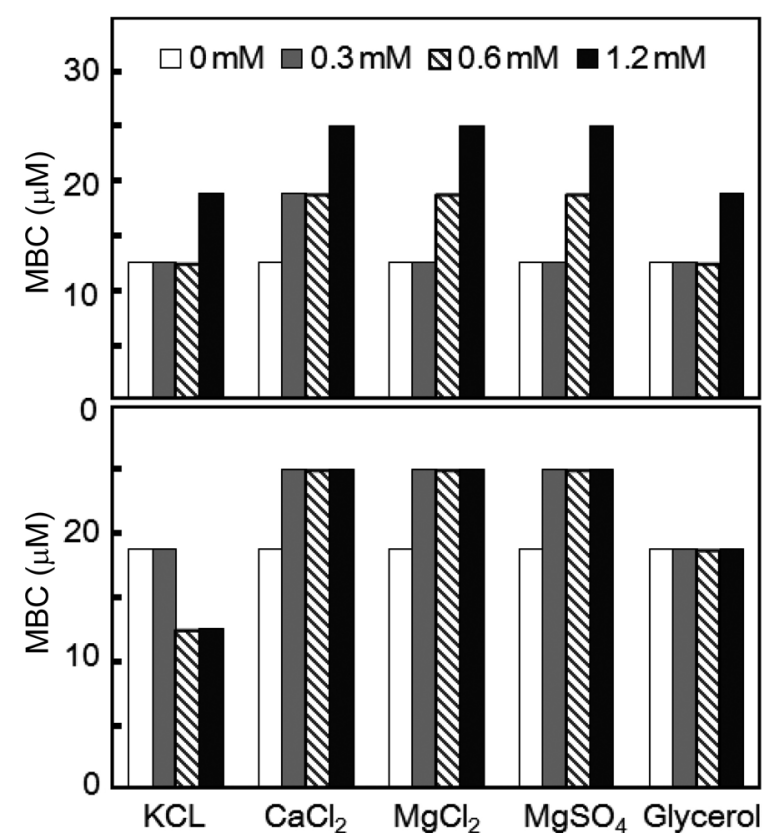

Fig. 1. Effects of cations and glycerol on the MIC and MBC of KCM21 against Clavibacter michiganensis subsp. michiganensis cells in LB media. MIC is shown in the upper panel and MBC is shown in the lower panel. The concentrations of the inorganic salts are shown in the legends. The concentrations of glycerol were $0 \%, 0.75 \%, 1.5 \%$, and $3 \%$, respectively, instead of the values in the legends.

$12.5 \mu \mathrm{M}$ at concentrations of $0.6 \mathrm{mM}$ and $1.2 \mathrm{mM}$ However, the effects of monovalent cations, $\mathrm{K}^{+}$on $\mathrm{KCM} 21$ action may not be significant since the 1.5 fold decrease was within the variations range of 2 fold, and MBCs were consistently higher than MICs in all other experiments. The MBC was $18.8 \mu \mathrm{M}$, while the MIC was $12.5 \mu \mathrm{M}$ in LB culture. In the presence of $12.5 \mu \mathrm{M}$ of KCM21, it was not possible to kill all $C$. michiganensis subsp. michiganensis cells, but it was enough to stop the growth suggesting a bacteriostatic nature of KCM21. Application of divalent cations could not eliminate the bactericidal activities of KCM21 completely at the concentration of $1.2 \mathrm{mM}$ but they could increase the MIC to $25 \mu \mathrm{M}$. Divalent cations $\left(\mathrm{Ca}^{2+}\right.$ and $\left.\mathrm{Mg}^{2+}\right)$ may not be directly involved in the bactericidal processes of KCM21 on C. michiganensis subsp. michiganensis cells, and may instead interact via an indirect mechanism such as an increase in the stability of the membrane for prevention of the direct interactions between KCM21 and potential target(s) of KCM21.

The MIC and MBC of KCM21 against Gram (-) P. syringae pv. tomato DC3000 cells were also monitored in the presence of various cations $\left(\mathrm{K}^{+}, \mathrm{Ca}^{2+}\right.$ and $\left.\mathrm{Mg}^{2+}\right)$ and glycerol. The $P$. syringae pv. tomato DC3000 cells showed

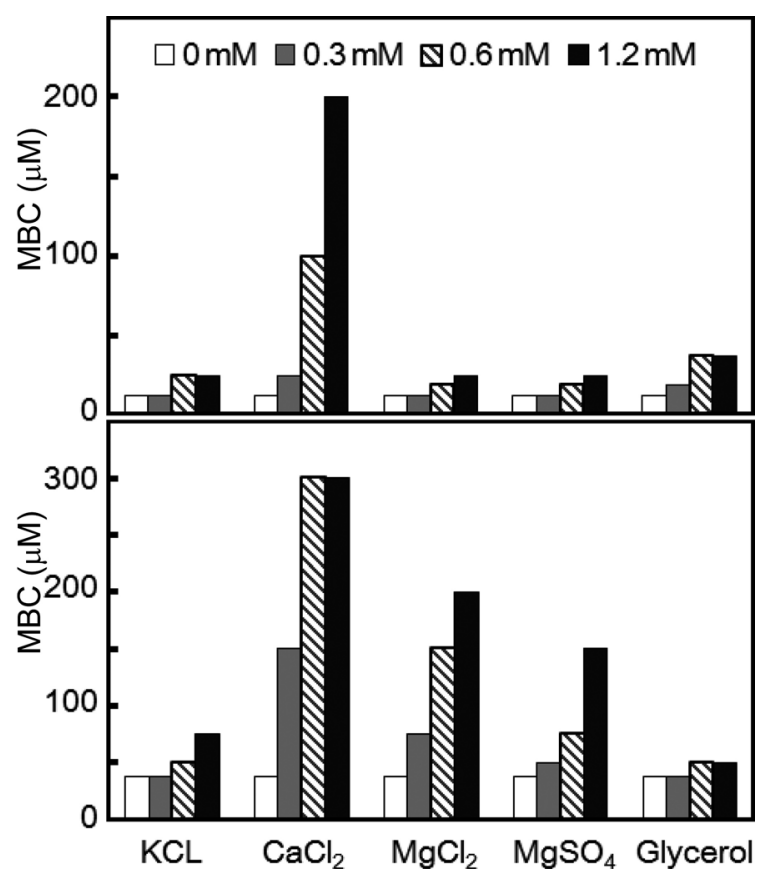

Fig. 2. Effects of cations and glycerol on the MIC and MBC of KCM21 against Pseudomonas. syringae pv. tomato DC3000 cells in LB media. MIC is represented in the upper panel and $\mathrm{MBC}$ is shown in the lower panel. The concentrations of the inorganic salts are shown in the legends. The concentrations of glycerol were $0 \%, 0.75 \%, 1.5 \%$, and $3 \%$, respectively, instead of the values in the legends.

stronger sensitivity to various cations and glycerol. In the presence of $\mathrm{Ca}^{2+}$, the MIC of KCM21 was increased by up to $200 \mu \mathrm{M}$ (16 fold), while the other salts and glycerol increased the MIC by only 2-3 fold. The MBCs also increased in response to various cations and glycerol, with the greatest increase being observed in response to calcium (8 fold) and magnesium (5.3 fold). The increase in MBC suggested that KCM21 act more bacteriostatically in the presence of divalent cations such as $\mathrm{Ca}^{2+}$ or $\mathrm{Mg}^{2+}$. Between the two magnesium containing salts, $\mathrm{MgCl}_{2}$ showed slightly higher inhibitory effects than $\mathrm{MgSO}_{4}$ (Fig. 2). Treatment with $\mathrm{MgCl}_{2}$ increased the $\mathrm{MBC}$ values dramatically (5.3 fold), while the fold increase for MIC was only 2 . For $P$. syringae pv. tomato $\mathrm{DC} 3000$ cells, $\mathrm{Mg}^{2+}$ ions led to a greater increase in $\mathrm{MBC}$ than MIC, which was contradictory to the finding that they had less effect on the MBC of $C$. michiganensis subsp. michiganensis cells.

Application of $\mathrm{CaCl}_{2}$ reduced the antibacterial activity of KCM21 significantly in the P. syringae pv. tomato DC3000 cells, while the activity was only reduced by 2 fold in the C. michiganensis subsp. michiganensis cells. Similar differences between Gram-positive and negative strains were also observed in other strains. In the presence 
of $1.2 \mathrm{mM} \mathrm{CaCl}_{2}$, the MIC of KCM21 increased by only 1.5 fold in Gram-positive Janibactor melonis cells, while it increased by about 10 fold in Gram-negative Xanthomonas oryzae pv. oryzae 710 (data not shown). These correlations within the same Gram strains indicate that the different effects of $\mathrm{CaCl}_{2}$ on the antibacterial activities of the two types of cells may be due to fundamental differences in the cell wall and membrane structure of the Gram-positive and negative strains. Gram-negative bacteria possess an outer membrane composed of lipopolysaccharide (LPS), which is held together by $\mathrm{Ca}^{2+}$ or $\mathrm{Mg}^{2+}$ that bridge negatively charged phosphosugars. Addition of cationic peptides such as KCM21 results in displacement of metal or damage to the outer membrane and facilitates entry of additional molecules from the exterior (Hancock and Chapple, 1999). Therefore, application of $\mathrm{Ca}^{2+}$ or $\mathrm{Mg}^{2+}$ would compete for the sites and result in antagonistic effects against the action of KCM21. In Gram-negative bacteria, the outer membrane with LPS appears to act as an additional barrier preventing entry of KCM21 into the cytoplasmic membrane in the presence of $\mathrm{Ca}^{2+}$ or $\mathrm{Mg}^{2+}$. Gram-positive bacterial cells have a thick cell wall structure composed of negatively charged components such as teichoic acids. In this case, divalent cations may alter the structures or compositions of the cell wall to interfere with the normal entrance of KCM21. The KCM21 would ultimately enter the cytoplasmic membrane, resulting in bactericidal activity. The divalent cations may inhibit the entrance of KCM21 in a different manner depending on the structures of Grampositive and Gram-negative strains, respectively.

Many studies have suggested that application of cations reduces bactericidal activities or increases the resistance to AMPs (Hancock, 1997; Hancock and Chapple, 1999). A few potential mechanisms were suggested by investigations of the resistance of Listeria sp. to nisin, an AMP produced by lactobacteria (Abee et al., 1994; Crandall and Montville, 1998). The isolated nisin resistant strain $\left(\mathrm{Nis}^{\mathrm{r}}\right)$ Listeria sp. showed reduced amounts of anionic phospholipids, as well as altered fatty acid content consistent with a more rigid membrane. The resistance of the $\mathrm{Nis}^{\mathrm{r}}$ cells was dependent on divalent cations; however, for the wild-type cells, divalent cations did not alter the sensitivity to nisin. The insensitivity of wild-type strain to the divalent cations suggested that the divalent cation dependent resistance of $\mathrm{Nis}^{\mathrm{r}}$ cells may not be established due to simple inhibition of the electrostatic interactions between the positive charges on the nisin molecule and negatively charged phospholipid head-groups. This suggests that divalent cations may increase their resistance by altering membrane properties. Divalent cations neutralize the negative head group charges and induce condensation of these phospholipids, resulting in a more rigid membrane. The results observed for the Gram-negative strain $P$. syringae pv. tomato DC3000 in the present study support that increased resistance to KCM21 in the presence of cations could be accomplished by alteration of membrane rigidity, rather than simple inhibition by electrostatic interactions. If the sensitivity to KCM21 decreased simply because of the reduction in electrostatic interactions, the sensitivities to KCM21 in the presence of $\mathrm{Ca}^{2+}$ and $\mathrm{Mg}^{2+}$ would be the same since both ions have +2 charges, while the $\mathrm{K}^{+}$should have about half the effect of the divalent cations. However, the calcium ion led to a greater increase in MBC than the magnesium ion, while the monovalent potassium ions showed very limited impacts on the sensitivity to KCM21.

In this study, calcium ion inhibited the bactericidal effect of KCM21 against $P$. syringae pv. tomato DC3000 cells to a greater degree than magnesium ion. Several studies have shown that the inhibitory effects of divalent cations appear to differ depending on the type of AMPs or their mode of action (Hancock and Chapple, 1999; Lawyer et al., 1996; Sugiarto and Yu, 2007; Wei and Bobek, 2005). For example, Lawyer et al. (1996) isolated innate 13-aminoacid AMP (Peptide 1) from porcine cells and showed that the antimicrobial activity was almost completely abolished upon treatment with $2 \mathrm{mM}$ of $\mathrm{MgCl}_{2}$; however, only a $20 \%$ reduction was observed in response to the same concentration of $\mathrm{Ca}^{2+}$. They suggested that $\mathrm{Mg}^{2+}$ may directly affect the activity by changing the conformation of the peptide or influencing cellular factors that augment the bactericidal effects of the peptide. In this context, it is worth noting that some autolytic enzymes are strongly inhibited by $\mathrm{Mg}^{2+}$. Kim et al. (1982) reported that a suicide enzyme known as autolysin, which is involved in the autolysis of bacteria, is strongly inhibited by $\mathrm{Mg}^{2+}$. Therefore, the action of peptide 1 may involve such autolysis of cellular autolytic enzymes that are inhibited by $\mathrm{Mg}^{2+}$. Our findings showed that $\mathrm{Ca}^{2+}$ had stronger inhibitory effects than $\mathrm{Mg}^{2+}$, suggesting that the inhibitory effect of divalent cations on the bactericidal activity of KCM21 was not involved with autolysin activity.

Kinetics of bactericidal activity of KCM21. Since MBC could monitor the actual bactericidal activity of the hexapeptides without interference from bacteriostatic activities, the time dependent killing process was evaluated based on the MBC with or without application of $\mathrm{Ca}^{2+}(0.3 \mathrm{mM})$.

Both bacterial strains had similar MBC $(25 \mu \mathrm{M})$ in LB culture. When an initial bactericidal assay was performed with $12.5 \mu \mathrm{M} \mathrm{KCM} 21$ in phosphate buffer, no 


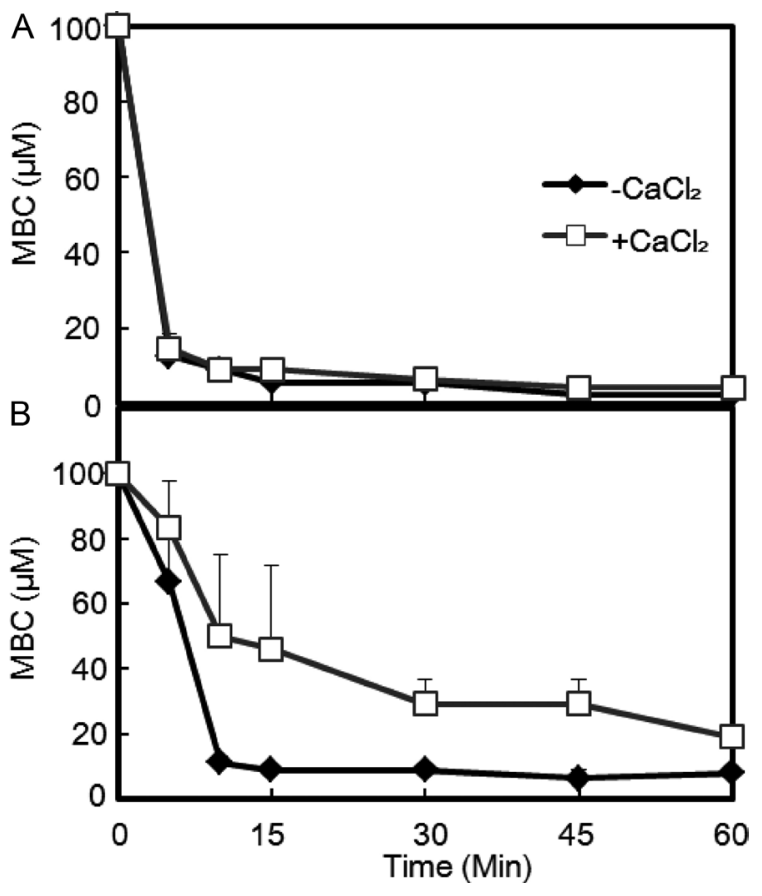

Fig. 3. Different effects of $\mathrm{Ca}^{2+}$ on the MBCs of KCM21 against the two bacterial strains. The bactericidal activity of KCM21 was assayed in phosphate buffer system. The MBCs of both bacterial strains were decreased rapidly. An application of $\mathrm{CaCl}_{2}(0.3 \mathrm{mM})$ significantly delayed the decrease of $\mathrm{MBC}$ against Peudomonas. syringae pv. tomato DC3000 cells (B), but not against Clavibacter michiganensis subsp. michiganensis cells (A).

colonies of either strain were observed within $10 \mathrm{~min}$. To obtain more information, the experiment was redesigned by varying the time and concentrations. The $\mathrm{MBC}$ of $C$. m. subsp. michiganensis cells was $12.5 \mu \mathrm{M}$ within $5 \mathrm{~min}$, while it was reduced to $2.4 \mu \mathrm{M}$ within $60 \mathrm{~min}$ in sodiumphosphate buffer, representing an approximately 10 -fold decrease when it was compared with the MBC in the LB culture (Fig. 3). The difference of MBCs between LB medium and phosphate buffer likely reflected the different ionic strengths of each solution. The MBC decreased rapidly with time, and all the cells were killed within $5 \mathrm{~min}$ in the presence of $12.5 \mu \mathrm{M}$. These findings indicate that the bactericidal process started almost immediately for $C . m$. subsp. michiganensis cells.

The P. s. pv. tomato DC3000 cells showed different bactericidal kinetics. The MBC of $P$. s. pv. tomato DC3000 cells was $66.7 \mu \mathrm{M}$ within $5 \mathrm{~min}$, but was reduced to 8.1 $\mu \mathrm{M}$ within $60 \mathrm{~min}$ in phosphate buffer. When compared with the MBC $(25 \mu \mathrm{M})$ in LB media, the MBC $(8.1 \mu \mathrm{M})$ in phosphate buffer was about three fold lower. The MBC decreased with time; however, the rate of decrease was slower than that of C. m. subsp. michiganensis cells. Both strains had the same MBC in LB medium, and their MBCs were reduced in phosphate buffer; however, the MBC for $P$. $s$. pv. tomato DC3000 cells was higher $(8.1 \mu \mathrm{M})$ than that of C. m. subsp. michiganensis cells $(2.4 \mu \mathrm{M})$ (Fig. 3). Considering the complex nature of LB medium, which includes various cations, anions, and macromolecules, the decrease in $\mathrm{MBC}$ of the two strains in phosphate buffer suggests that some of the some molecules in LB medium may hinder the normal bactericidal activity of KCM21. These hindrances appear to work differently depending on the cell types through unique interactions with different types of membrane structures.

Application of $\mathrm{Ca}^{2+}$ caused distinct responses in the two types of bacterial cells. The MBC of C. m. subsp. michiganensis cells was increased up to 2 fold upon application of $\mathrm{Ca}^{2+}$ and did not delay the killing process since the time dependent decrease of MBC was almost same. For P. s. pv. tomato DC3000 cells, the killing process appeared to be delayed in the presence of $\mathrm{Ca}^{2+}$, as indicated by $60 \mathrm{~min}$ being required to kill all bacteria at a concentration of $25 \mu \mathrm{M}$, which was 6 times slower than without $\mathrm{Ca}^{2+}$. In the presence of $\mathrm{Ca}^{2+}, \mathrm{MBCs}$ increased by about 5 fold in P. s. pv. tomato DC3000 cells within 45 min.

The differences in $\mathrm{Ca}^{2+}$ dependency may rely on the fundamental structural differences between Gram-positive and Gram-negative bacterial strains, especially the fact that Gram-negative bacteria have an extra outer membrane. It is possible that the outer membrane prevents $\mathrm{KCM} 21$ from reaching the cytoplasmic membrane or other cytosolic target sites. In the presence of high concentrations of KCM21, the outer membrane itself could be disrupted and may not work as a barrier to prevent KCM21 from entering the cytosol. Considering its rapid working time (complete cell death in $10 \mathrm{~min}$ or less in the presence of $12.5 \mu \mathrm{M}$ of KCM21), metabolic interference by the hexapeptide may not be a reasonable cause of bactericidal activity. Our findings suggested that the hexapeptide KCM21 may interact with cytoplasmic membrane or critical components inside the cells in a short time and disintegrate or destroy its functions. The cytoplasmic membrane could be a reasonable target for KCM21, and cytosolic macromolecules such as RNA, DNA or enzymes with critical function are also possible targets for KCM21.

Effects of KCM21 treatment on bacterial cell morphology. To illustrate the impact of antibacterial activity of KCM21, SEM and TEM analysis were performed. In all experiments, high $(100 \mu \mathrm{M})$ and low $(6.25 \mu \mathrm{M})$ concentrations were tested. TEM analysis revealed that the number of $C$. michiganensis subsp. michiganensis cells seemed to 


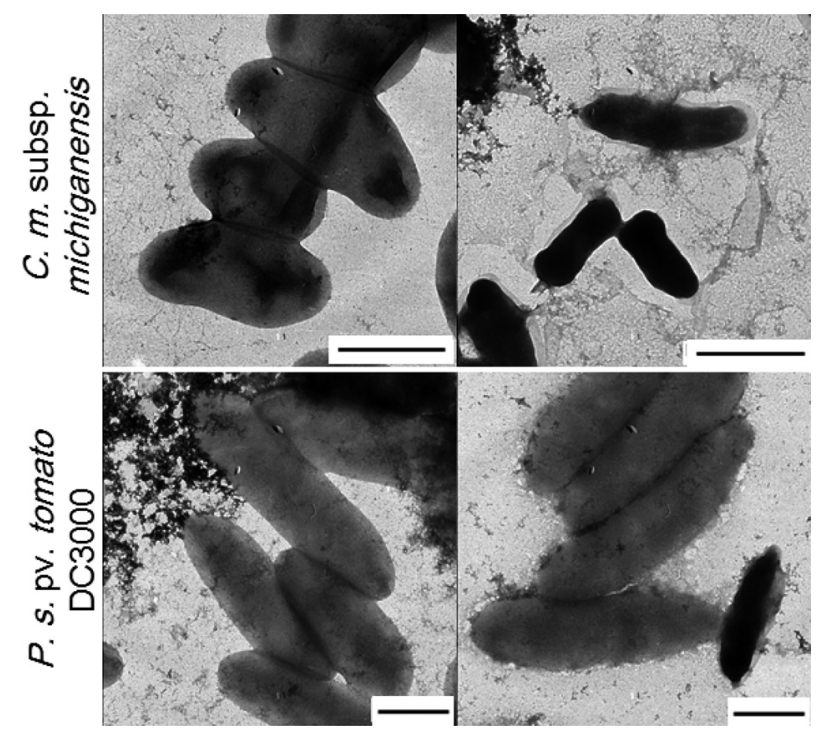

Fig. 4. Effects of KCM21 on the two bacterial strains examined by transmission electron microscopy (TEM). Clavibacter michiganensis subsp. michiganensis cells are shown in the upper panels and Pseudomonas. syringae pv. tomato DC3000 cells are shown in the lower panels. Intact cells are shown in the left column, while cells treated with KCM21 $(100 \mu \mathrm{M})$ for $30 \mathrm{~min}$ in phosphate buffer are shown in the right column (Bar: $1 \mu \mathrm{m})$.

be decreased since it was difficult to find cells in a microscopic field in the presence of $100 \mu \mathrm{M} \mathrm{KCM} 21$. Most of $C$. michiganensis subsp. michiganensis cells that were found appeared dark and shrunken, and more dark and shrunken cells were observed as the concentration of KCM21 increased. For P. syringae pv. tomato DC3000 cells, there was no indication of significant decrease in cell number and the overall shape was intact, even though the surface of $P$. syringae pv. tomato DC3000 cells appeared slightly rough in the presence of $100 \mu \mathrm{M}$ of KCM21. A few $P$. s. pv. tomato DC3000 cells appeared dark and shrunken (Fig. 4). In the presence of low concentration $(6.25 \mu \mathrm{M})$, the overall cell surface appeared to be intact and a few dark shrunken cells were also observed. The reduction in the size of $C$. michiganensis subsp. michiganensis cells could be the result of leakage of internal contents due to partial disruption of the cytoplasmic membrane. The complete disruption of the cytoplasmic membrane would lead to cell lysis, resulting in the decreased cell number of $C$. michiganensis subsp. michiganensis. The darkening of the C. michiganensis subsp. michiganensis cells could be the result of internalization of the staining agent, uranyl acetate due to the partial disruption of the cytoplasmic membrane. Overall, KCM21 appeared to cause cell lysis or induce a dark shrunken phenotype for C. michiganensis subsp.

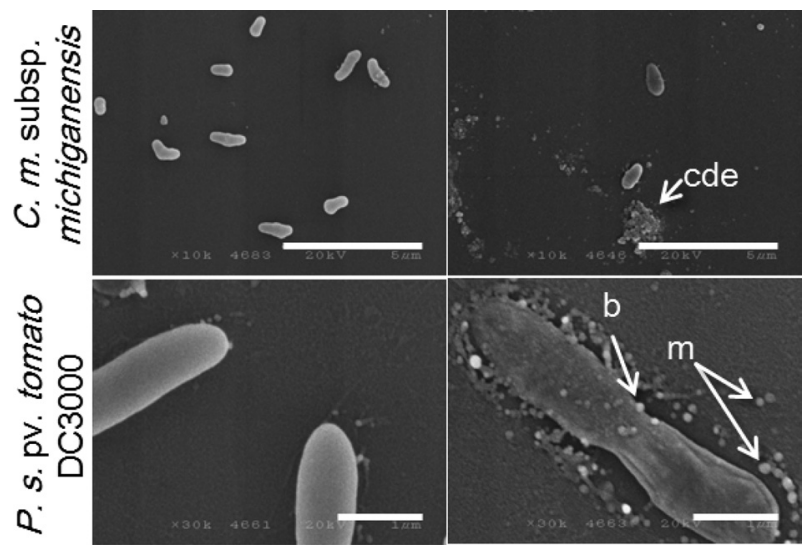

Fig. 5. Effects of KCM21 on the two bacterial strains examined by scanning electron microscopy (SEM). Clavibacter michiganensis subsp. michiganensis cells are shown in the upper panels and Pseudomonas. syringae pv. tomato DC3000 cells are shown in the lower panels. Intact cells are shown in the left column and cells treated with KCM21 $(100 \mu \mathrm{M})$ for $30 \mathrm{~min}$ in phosphate buffer are shown in the right column. cde: cell debris, m: micelles, b:blebs. (Bars: $5 \mu \mathrm{m}$ in upper panels and $1 \mu \mathrm{m}$ in lower panels).

michiganensis cells through disruption of cytoplasmic membrane integrity, while the majority of $P$. syringae pv. tomato DC3000 cells looked normal upon TEM analysis suggesting that the mode of killing of KCM21 for P. syringae pv. tomato DC3000 cells could be different from that of C. michiganensis subsp. michiganensis cells.

SEM analysis showed more distinct effects. In the presence of high concentrations $(100 \mu \mathrm{M})$, a decrease in cell number was indicated for $C$. michiganensis subsp. michiganensis cells. Agglutination of cell debris with irregular particles was observed suggesting that cell lysis had occurred (Fig. 5). There was also no indication of a significant decrease in cell number of $P$. syringae pv. tomato DC3000 in the presence of $100 \mu \mathrm{M}$ of KCM21, even though a few ghost-like cells were observed in which the cell contents were lost but the overall cell shape was partially maintained. The most distinct features observed in the P. syringae pv. tomato DC3000 cells treated with KCM21 were the formation of blebs that protruded from the surface of the cells. In addition to these, many independent micelles appeared around P. syringae pv. tomato DC3000 cells. The micelles were round and spherical, in contrast to the irregularly shaped particles observed in the cell debris of C. michiganensis subsp. michiganensis cells (Fig. 5). In the presence of low concentrations $(6.25 \mu \mathrm{M})$, a few blebs were observed on the cell surface of $P$. syringae pv. tomato DC3000 cells; however, the overall shape remained intact, and collapse of the cells was not observed. Overall, treat- 
ment with a lethal concentration of KCM21 $(100 \mu \mathrm{M})$ for 30 min would be sufficient to kill all of the bacterial cells; therefore, the cells observed upon EM analysis should be all dead. Interestingly, most of $P$. syringae pv. tomato DC3000 cells maintained cell integrity, while C. michiganensis subsp. michiganensis cells appeared to be lysed.

Although several studies have suggested lysis as a major mode of action of most AMPs, Hancock (2001) stated that there was little evidence for complete dissolution of the majority of bacterial cells at the minimum effective concentration. For example, EM analysis of an E. coli strain treated with 32 times the MIC of the peptide CEMA (a broad spectrum AMP) showed no apparent loss of underlying cell shape. However, the outer-membrane morphology adopted a blistered appearance. Overall, EM analysis revealed that KCM21 acted differently between Grampositive and Gram-negative stains, appearing to induce cell lysis for Gram-positive C. michiganensis subsp. michiganensis cells, but causing surface alterations in the Gramnegative $P$. syringae pv. tomato DC3000 cells without loss of the underlying cell shape.

KCM21 showed similar antimicrobial activities against C. michiganensis subsp. michiganensis and P. syringae pv. tomato DC3000 cells in LB media (Choi and Moon, 2009). In this study, modes of bactericidal activities of KCM21 were analyzed by using the two types of cells. The results revealed that the responses of $C$. michiganensis subsp. michiganensis and $P$. syringae pv. tomato DC3000 cells against KCM21 were quite different from each other. EM analysis indicated that many $C$. michiganensis subsp. michiganensis cells were ruptured by KCM21, while $P$. syringae pv. tomato DC3000 cells maintained the underlying cell shape accompanied by the formation of micelles surrounding the cells and blebs protruding from the cell surface. The application of divalent cations such as $\mathrm{Mg}^{2+}$ or $\mathrm{Ca}^{2+}$ to $\mathrm{LB}$ medium reduced the bactericidal activities of KCM21, and the reduction was more significant in $P$. syringae pv. tomato DC3000 cells than $C$. michiganensis subsp. michiganensis cells. KCM21 showed higher bactericidal activities for both stains in phosphate buffer than in LB media. C. michiganensis subsp. michiganensis cells were more sensitive to KCM21 than P. syringae pv. tomato DC3000 cells in phosphate buffer. The application of $\mathrm{CaCl}_{2}$ in phosphate buffer reduced the bactericidal activities of KCM21 and delayed bactericidal process against $P$. syringae pv. tomato DC3000 cells, but did not altered against $C$. michiganensis subsp. michiganensis cells significantly. These results suggest that KCM21 could kill both Gram-positive and Gram-negative strains effectively, but the mode of interactions of KCM21 with these cells would be quite different depending on the structures and compositions of the membranes of the Gram-positive and Gram-negative cells. AMPs are ancient and ubiquitous antimicrobial compounds found in almost all living organisms. Gram-positive and Gramnegative bacterial strains have evolved to develop their own functions and structures to avoid AMPs. Accordingly, each strain investigated herein showed its own way of dealing with antimicrobial peptides. Efforts to identify new effective AMPs and studies on the killing mechanisms of short AMPs like KCM21 would help us to understand the long evolutionary process for typical two types of bacteria to escape the deadly action of ubiquitous AMPs. These understanding would help us to find noble way to control bacterial diseases in plants.

\section{Acknowledgements}

This research was supported by Bio \& Medical Technology Development Program of the NRF funded by the Korean government (2012M3A9B2052871).

\section{References}

Abee, T., Rombouts, F. M., Hugenholtz, J., Guihard, G. and Letellier, L. 1994. Mode of action of nisin z against Listeria monocytogenes scott a grown at high and low temperatures. Appl. Environ. Microbiol. 60:1962-1968.

Anderson, P. K., Cunningham, A. A., Patel, N. G., Morales, F. J., Epstein, P. R. and Daszak, P. 2004. Emerging infectious diseases of plants: Pathogen pollution, climate change and agrotechnology drivers. Trends Ecol. Evol. 19:535-544.

Blondelle, S. E., Perez-Paya, E. and Houghten, R. A. 1996. Synthetic combinatorial libraries: Novel discovery strategy for identification of antimicrobial agents. Antimicrob. Agents Chemother. 40:1067-1071.

Blondelle, S. E., Takahashi, E., Houghten, R. A. and Perez-Paya, E. 1996. Rapid identification of compounds with enhanced antimicrobial activity by using conformationally defined combinatorial libraries. Biochem. J. 313:141-147.

Brogden, K. A. 2005. Antimicrobial peptides: Pore formers or metabolic inhibitors in bacteria? Nat. Rev. Microbiol. 3:238250 .

Choi, J. and Moon, E. 2009. Identification of novel bioactive hexapeptides against phytopathogenic bacteria through rapid screening of a synthetic combinatorial library. J. Microbiol. Biotechnol. 19:792-802.

Concannon, S. P., Crowe, T. D., Abercrombie, J. J., Molina, C. M., Hou, P., Sukumaran, D. K., Raj, P. A. and Leung, K. P. 2003. Susceptibility of oral bacteria to an antimicrobial decapeptide. J. Med. Microbiol. 52:1083-1093.

Crandall, A. D. and Montville, T. J. 1998. Nisin resistance in Lis- 
teria monocytogenes ATCC 700302 is a complex phenotype. Appl. Environ. Microbiol. 64:231-237.

Hancock, R. E. 1997. Antibacterial peptides and the outer membranes of gram-negative bacilli. J. Med. Microbiol. 46:1-3.

Hancock, R. E. and Chapple, D. S. 1999. Peptide antibiotics. Antimicrob. Agents Chemother. 43:1317-1323.

Hancock, R. E. and Lehrer, R. 1998. Cationic peptides: A new source of antibiotics. Trends Biotechnol. 16:82-88.

Hancock, R. E. and Sahl, H. G. 2006. Antimicrobial and hostdefense peptides as new anti-infective therapeutic strategies. Nat. Biotechnol. 24:1551-1557.

Houghten, R. A. 2000. Parallel array and mixture-based synthetic combinatorial chemistry: Tools for the next millennium. Annu. Rev. Pharmacol. Toxicol. 40:273-282.

Houghten, R. A., Appel, J. R., Blondelle, S. E., Cuervo, J. H., Dooley, C. T. and Pinilla, C. 1992. The use of synthetic peptide combinatorial libraries for the identification of bioactive peptides. Biotechniques 13:412-421.

Houghten, R. A., Pinilla, C., Appel, J. R., Blondelle, S. E., Dooley, C. T., Eichler, J., Nefzi, A. and Ostresh, J. M. 1999. Mixture-based synthetic combinatorial libraries. J. Med. Chem. 42:3743-3778.

Houghten, R. A., Pinilla, C., Blondelle, S. E., Appel, J. R., Dooley, C. T. and Cuervo, J. H. 1991. Generation and use of synthetic peptide combinatorial libraries for basic research and drug discovery. Nature 354:84-86.

Kim, K. S., Morrison, J. O. and Bayer, A. S. 1982. Deficient autolytic enzyme activity in antibiotic-tolerant lactobacilli. Infect. Immun. 36:582-585.

Lawyer, C., Pai, S., Watanabe, M., Borgia, P., Mashimo, T., Eagleton, K. and Watanabe, K. 1996. Antimicrobial activity of a 13 amino acid tryptophan-rich peptide derived from a putative porcine precursor proten of a novel family of atibacterial prptides. FEBS Lett. 390:95-98.

Lemaitre, B. and Hoffmann, J. 2007. The host defense of Drosophila melanogaster. Annu. Rev. Immunol. 25:697-743.

Lopez-Garcia, B., Gonzalez-Candelas, L., Perez-Paya, E. and Marcos, J. F. 2000. Identification and characterization of a hexapeptide with activity against phytopathogenic fungi that cause postharvest decay in fruits. Mol. Plant-Microbe Inter- act. 13:837-846.

Lopez-Garcia, B., Perez-Paya, E. and Marcos, J. F. 2002. Identification of novel hexapeptides bioactive against phytopathogenic fungi through screening of a synthetic peptide combinatorial library. Appl. Environ. Microbiol. 68:2453-2460.

Miyasaki, K. T., Iofel, R., Oren, A., Huynh, T. and Lehrer, R. I. 1998. Killing of Fusobacterium nucleatum, Porphyromonas gingivalis and Prevotella intermedia by protegrins. J. Periodental Res. 33:91-98.

Munoz, A., Lopez-Garcia, B., Perez-Paya, E. and Marcos, J. F. 2007. Antimicrobial properties of derivatives of the cationic tryptophan-rich hexapeptide paf26. Biochem. Biophys. Res. Commun. 354:172-177.

Reddy, K. V., Yedery, R. D. and Aranha, C. 2004. Antimicrobial peptides: Premises and promises. Int. J. Antimicrob. Agents 24:536-547.

Sal-Man, N., Oren, Z. and Shai, Y. 2002. Preassembly of membrane-active peptides is an important factor in their selectivity toward target cells. Biochemistry 41:11921-11930.

Sugiarto, H. and Yu, P. L. 2007. Effects of cations on antimicrobial activity of ostricacins-1 and 2 on E. coli O157:H7 and $S$. aureus 1056MRSA. Curr. Microbiol. 55:36-41.

Sundin, G. W. and Bender, C. L. 1993. Ecological and genetic analysis of copper and streptomycin resistance in Pseudomonas syringae pv. syringae. Appl. Environ. Microbiol. 59:1018-1024.

Vidaver, A. K. 2002. Uses of antimicrobials in plant agriculture. Clin. Infect. Dis. 34:107-110.

Wei, G. X. and Bobek, L. A. 2005. Human salivary mucin muc7 12-mer-l and 12-mer-d peptides: Antifungal activity in saliva, enhancement of activity with protease inhibitor cocktail or edta, and cytotoxicity to human cells. Antimicrob. Agents Chemother. 49:2336-2342.

Yeaman, M. R. and Yount, N. Y. 2003. Mechanisms of antimicrobial peptide action and resistance. Pharmacol. Rev. 55:27-55.

Yedery, R. D. and Reddy, K. V. 2005. Antimicrobial peptides as microbicidal contraceptives: Prophecies for prophylactics-a mini review. Eur. J. Contracept. Reprod. Health. Care. $10: 32-42$. 